\title{
Cross-Sectional Study of Tuberculosis and HIV/AIDS Co-Infections among Patients Attending Directly Observed Treatment Centers in Bayelsa State, Nigeria
}

\author{
Amala Smart Enoch ${ }^{1 *}$, Goodluck Silas ${ }^{1}$, Monsi Tombari Pius ${ }^{1}$, Innocent Agbesor Nwozuke² \\ ${ }^{1}$ Department of Medical Laboratory Science, Rivers State University, Port Harcourt, Rivers State, Nigeria \\ ${ }^{2}$ Medical Laboratory Division, Department of Medical Services, National Assembly Clinic, Three Arm Zone, Garki, Abuja \\ Email: *amala.smart@ust.edu.ng
}

How to cite this paper: Enoch, A.S., Silas, G., Pius, M.T. and Nwozuke, I.A. (2021) Cross-Sectional Study of Tuberculosis and HIV/AIDS Co-Infections among Patients Attending Directly Observed Treatment Centers in Bayelsa State, Nigeria. Journal of Tuberculosis Research, 9, 131-145.

https://doi.org/10.4236/jtr.2021.93013

Received: May 20, 2021

Accepted: August 9, 2021

Published: August 12, 2021

Copyright $\odot 2021$ by author(s) and Scientific Research Publishing Inc. This work is licensed under the Creative Commons Attribution International License (CC BY 4.0).

http://creativecommons.org/licenses/by/4.0/

\begin{abstract}
Introduction: Mycobacterium tuberculosis (TB) infects about one quarter of the global population and is transmitted via aerosols by coughing, sneezing, etc. Some socio-behavioral factors may predispose an individual to the disease. Methodology: The study used a cross-sectional design with random stratified sampling technique. Sputum samples from suspected TB patients totaling 600 were obtained from patients attending directly observed treatment (DOTs) centers from different local government areas in Bayelsa. The sputum samples were examined for tuberculosis using the Ziehl-Neelsen staining technique and Gene Xpert molecular method while HIV/AIDS tests were carried out with EDTA blood using the Alere HIV12 test kit and others. Results: The Prevalence of TB by Gene Xpert was 294 (49.0\%) and by AFB 217 (36.1\%), while TB/HIV co-infection was 94 (32.0\%), RRMTB was 34 (11.9\%) and HIV 249 (41.5\%). Prevalence by age group showed the $20-39$ years had the highest prevalence of TB 98 (47.0\%), TB/HIV 35 (47.0\%), RRMTB 17 (48.0\%) and HIV 90 (57.0\%). By gender the male had slightly higher prevalence of TB 109 (52.0\%), TB/HIV 51 (54.0\%), RRMTB 20 (56.0\%) and HIV 126 (51.0\%) than the female. Prevalence among smokers and alcoholics and subjects who engaged in both habits had high prevalence TB 109 (37.0\%), TB/HIV 14 (40.0\%), RRMTB 14 (40.0\%) and HIV 72 (29.0\%). For educational status those with tertiary and secondary education had similar high prevalence and for occupation, the self-employed and civil servants had similar elevated prevalence. The prevalence by local government area showed that Yenegoa had the highest with TB 235 (80.0\%), TB/HIV 72 (76.6\%), RRMTB 24 (68.5\%) and HIV 202 (81.2\%). Conclusion: An increase in the development of resistance by M. tuberculosis
\end{abstract}


also contributes to the persistence of the disease as well as some socio-economic factors.

\section{Keywords}

Tuberculosis, HIV/AIDS, Co-Infection, Dots Centers, Bayelsa

\section{Introduction}

Tuberculosis (TB) is the most frequent cause of death from a single infectious agent and tuberculosis is spread when people infected with the Bacilli expel aerosols carrying the bacterium into the air by coughing, sneezing, etc. [1] Worldwide TB is one of the top 10 causes of death [2]. The World Health Organization estimated that $13 \%$ of 8.6 million new TB cases in 2012 were co-infected with HIV resulting in 1.3 million TB-related deaths [3]. In 2013, Global AIDS reported an increase in the number of TB co-infected with HIV receiving antiretroviral treatment. This was about $80 \%$ of HIV-positive persons with TB worldwide [4]. HIV infection accelerates the development of latent TB into active TB disease [5]. The incidences of TB, TB/HIV and multidrug-resistant TB have increased in recent years and frustrated the measures to control TB [6] [7]. TB causes the suppression of the immune system of the infected individual and reduces life span if prophylactic measures are not employed [8]. The incidence of TB is on increase in Sub-Saharan Africa and TB is a major factor contributing to death among people living with HIV/AIDS [9].

In developing countries, stigma, culture, barriers to testing and treatment, poor health care settings, health-related illiteracy, lack of man power, shortage of medical equipment, and lack of laboratory facilities were associated with TB, TB/HIV infection [10]. Consumption of alcohol and tobacco smoking are linked to TB infection by reduction of immunity [11] [12] [13]. Social bereavement such as education, low income, unemployment, etc., is associated with TB [14]. More than three persons living in a room, increased household and overcrowding predisposes to TB because the infection is transmitted by inhalation of aerosols containing the bacterium [15] [16]. Umeh et al. [17] reported a $12.8 \%$ prevalence of HIV/TB co-infection in Nigeria.

The WHO African region accounted for 25\% incidence of TB/HIV globally and Nigeria accounts for $8 \%$ of cases per 100,000 population in 2016 [18]. People that fall within certain age groups have been might be more predisposed to TB and HIV/AIDS [19] [20] [21]. The prevalence of TB/HIV co-infection in African countries was $31.25 \%$. Studies from West African Countries had shown the prevalence of TB in Ghana was 32.5\%, Mali 25.9\%, and Burkina Faso $40.5 \%$. TB affects all countries and ages but it was estimated in 2018 that $90 \%$ were adult [22].

About $21 \%$ of previously treated cases were likely to have MDR/RR-TB in the same year [23]. MDR-TB is related to strains of M. tuberculosis resistant to iso- 
niazid and rifampicin the first-line drugs. Drug-resistant TB (MDR-TB) patients require treatment for a longer period and more expensive treatment using second-line medications that are less effective and more toxic [24] Geographically, most TB cases in 2018 were in the World Health Organization (WHO) regions of South-East Asia (44\%), Africa (24\%) (WHO 2018) [22]. This study aimed to determine the prevalence of TB, TB/HIV co-infection, RRMTB, HIV, and other factors that may be linked to TB. To compare the results obtained with the finding to those of other researchers.

\section{Materials and Methods}

\subsection{Study Area}

The studies were conducted in the nine (9) Local Government Areas of Bayelsa State, Nigeria. The state has a population of 1.7 million people, located between latitude $4^{\circ} 15^{\prime}$ North and latitude $5^{\circ} 23^{\prime}$ South and longitude $5^{\circ} 22^{\prime}$ West, $6^{\circ} 45^{\prime}$ East. It has a boundary with Delta State in the North, Rivers State in the East, and the Atlantic Ocean on the West and South. The population is made of both the indigenes mainly Ijaws and non-indigenes.

\subsection{Collection Samples}

Samples were collected from TB suspects in Directly Observed Treatment, Shortcourse (DOTS) centers at the Federal Medical Center, Yenagoa, Tuberculosis/ Leprosy Center Igbogene, Niger Delta University Health Centre Amasoma, Federal Medical Center Otuoke, Comprehensive Health Centre Nembe, Cottage Hospital Okpuma, Comprehensive Health Centre Ekeremor, Comprehensive Health Centre Kiama and General Hospital Sagbama all in Bayelsa State. Stratified random sampling was used

\subsection{Ethical Consideration}

Written consent was obtained from each of the subjects before administering the questionnaire for demographic information and other data collection. Blood and sputum samples were collected separately from each patient into the appropriate container and labeled properly for examinations.

\subsection{Sample Size}

The sample size was determined statistically with the formula:

$$
N=z^{2} p \frac{(1-p)}{e^{2}}
$$

where $N=$ minimum sample size, $Z=$ standard normal deviant curve at $95 \%=$ 1.96, $P=$ Prevalence of TB/HIV co-infection $=25 \%, E=$ precision/error margin $=5 \%(0.05)$.

$$
N=3.8416 \frac{0.25 \times 0.75}{0.0025}
$$


$N=288$ minimum sample size,

$10 \%$ Non-response $10 / 100 \times 288=28.8=29$.

Thus, the minimum sample size is $288+29=317$. However, the sample size was increased to 600 subjects in order to make the work more representative of the population.

\subsection{Study Design}

This work used a cross-sectional study cohort study of individuals with tuberculosis and HIV co-infection. The sampling technique used was random stratified method. The stratification method used was gender and locality. Patients attending DOTS clinic at DOTS centers in Bayelsa State, Nigeria. Patient must resident in Bayelsa State, and permission from the guardian for the patient below 18 years. The patient must have signs or symptoms of TB or HIV and those below 2 years or above 100 years were excluded.

\subsection{Sample Preparation (Sputum)}

The cover of each sputum container was unscrewed and the volume of the sputum required was measured with the already graduated screw cap sputum container used for collection. Using a sterile disposable pipette, the sample reagent at 2:1 (v/v) ratio of the sputum sample was added and the cover of the container was properly replaced tightly and vigorously. The sample was incubated at room temperature for 10 minutes and mixed again, then incubated for another 5 minutes.

\subsection{Cartridge Preparation}

The Gene Xpert MTB/RIF cartridge was labeled with the same number as on the sputum container which was incubated for 5 minutes. Using the provided sterile disposable transfer pipette with the Gene Xpert kits, $2 \mathrm{ml}$ of the liquefied sample was withdrawn and transferred into the open port of the Gene Xpert Cartridge. The cartridge was then taken to the Gene Xpert machine for processing.

\subsection{Ziehl-Neelsen Staining Technique}

The procedure for the Ziehl-Neelsen Staining technique was carried out as described by Chessbrough [25].

\subsection{Pre-Counseling for HIV Test and Sample Collection}

Each subject was informed of the type of test to be conducted with the blood sample obtained. The required procedures and written consent were obtained from each subject for HIV testing. Hand gloves are worn and the site for puncture was cleaned with cotton soaked in $70 \%$ alcohol. Blood was withdrawn by venipuncture of the median cubital vein. The area was allowed to dry for about 30 seconds and the needle was introduced with bevel up, $2 \mathrm{ml}$ of blood were withdrawn and the tourniquet was released. The needle was disposed of in a sharps disposal container and blood was transferred into an EDTA sample bottle and mixed by 
gentle inversion.

\subsection{Procedure Used for HIV Testing.}

HIV Rapid test procedure was done using Alere Determine HIV1/2 test kit. The materials were Alere Determine HIV1/2 test kits, micropipette, timer, chase buffer, and patient blood sample. $50 \mathrm{ul}$ of the patient whole blood was transferred to the sample pad. One drop of chase buffer was dropped after applying the sample, and it was timed for 15 minutes. Results were read and recorded. The doublecheck method was done using Trinity Biotech Uni gold. Sixty microliters $(60 \mu \mathrm{l})$ of whole patient blood was dispensed into the well of the device and two drops of the assay diluents were added to the well. It was timed for 10 minutes, and the result was read and recorded. HIV testing using Chembio HIV1/2 STAT-PAK was carried out. It was labeled and $5 \mu \mathrm{l}$ of patient blood was added into the sample well of the device. Two hundred milliliters $(200 \mathrm{ml})$ of the buffer were also added to the sample well and timed for 10 minutes. Results were read and recorded after 10 minutes.

\subsection{Statistics}

The results were represented in percentages. Where appropriate, data analyses were carried out using Chi-Square or Fischer's exact test in GraphPad Prism Software Version 8.0.2, San Di-ego, CA. The analyses were considered to be significant at a $95 \%$ confidence interval (CI) at a p-value less than 0.05 .

\section{Results}

\subsection{The Prevalence of TB, TB/HIV, RRMTB and HIV}

Out of the 600 sputum samples examined, 294 (49.0\%) were positive for TB by Gene Xpert analysis, while 217 (36.1\%) were positive by using ZN-stain method, 249 (41.5\%) were HIV positive, 94 (31.9\%) were co-infected with TB/HIV and 34 (11.9\%) had RRMTB as shown on Table 1.

\subsection{The Prevalence of TB, TB/HIV, RRMTB and HIV by Age Groups}

Age group $\leq 19$ yrs were 68, the prevalence of TB was 18 (8.5\%), TB/HIV 9 (28.0\%) RRMTB 2 (8.0\%) and HIV 34 (19.0\%), age group 20 - 39 yrs were 205 with a prevalence of 98 (47.0\%), HIV/TB 35 (47.8\%), RRMTB $12(48.0 \%)$ and HIV 90 (51.0\%), while 105 fell within age group $40-59$ yrs the prevalence of TB was 63 (39.0\%), HIV/TB 20 (29.9\%), RRMTB 5 (20.0\%) and HIV 40 (22.0\%), Age group 60 - 79 yrs were 50, 31 (15.0\%), TB/HIV 6 (8.9\%), RRMTB 6 (24.0\%), and HIV $14(8.0 \%)$ as shown in Figure 1.

\subsection{The Prevalence of TB, TB/HIV, RRMTB and HIV by Gender}

Out of the 600 subjects examined 291 (48.5\%) were male, the prevalence of TB among them was 109 (52.0\%), TB/HIV 51 (54.0\%), RRMTB 20 (56.0\%) and HIV 126 (51.0\%) while the prevalence among 309 (51.5\%) females was TB 141 
(48.0\%),TB/HIV 43 (46.0\%), RRMTB 15 (44.0\%) and HIV 122 (49.0\%), as shown on Figure 2.

\subsection{Prevalence of TB, HIV, TB/HIV and RRMT among Alcoholics and Smokers}

Out of 600 subjects examined $166(27.7 \%)$ were alcoholic and 97 (33.0\%) had

Table 1. Prevalence of TB, TB/HIV, RRMTB and HIV.

\begin{tabular}{ccc}
\hline Variable & Number Examined & Number Positive \\
\hline Identification Method & 600 & $294(49.0)$ \\
TB (Gene Xpert) & 600 & $217(36.1)$ \\
TB (ZN-stain) & & \\
Prevalence of Diseases & 294 & $94(32.0)$ \\
TB/HIV & 294 & $34(11.6)$ \\
RRMTB & 294 & $200(68.0)$ \\
TB Only & 600 & $249(41.5)$ \\
HIV &
\end{tabular}

KEY: TB = Tuberculosis, TB/HIV = Tuberculosis and Human Immunodeficiency Virus co-infection RRMTB = Rifampicin Resistance Mycobacterium tuberculosis, HIV = Human Immunodeficiency Virus, Numbers in Parenthesis $=$ Percentages

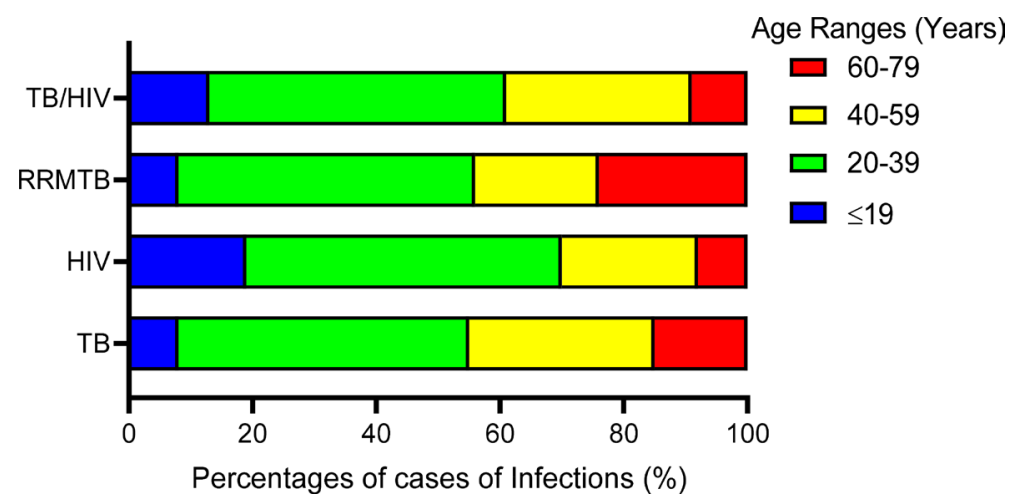

Figure 1. The Prevalence of TB, TB/HIV, RRMTB and HIV by Age Groups. Key: Chisquare: 21.85 , df: $9, \mathrm{p}=0.0094$.

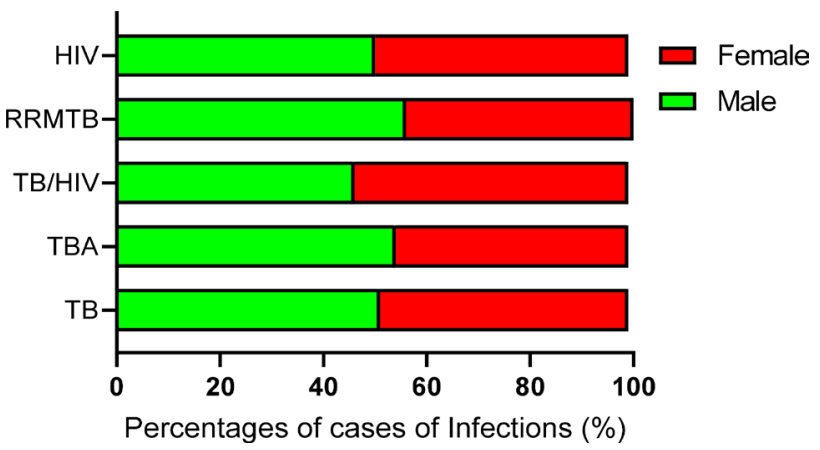

Figure 2. Prevalence rates of TB, TB/HIV, RRMTB and HIV by Gender. Key: Chi-square: 1.536, df: $4, \mathrm{p}=0.8202$. 
TB, 28 (30.0\%) had TB/HIV co-infection, 11 (32.0\%) had RRMTB and HIV was 75 (30.0\%); 80 (13.3\%) were smokers 41 (15.0\%) had TB, 14 (15.0\%) had TB/ HIV co-infection, 6 (16.0\%) were RRMTB positive and 37 (15.0\%) were HIV positive; those who indulge in both alcohol and smoking were 168 (28.0\%) and 109 (37.0\%) had TB, 42 (45.0\%) were co-infected with TB/HIV, 14 (40.0\%) were RRMTB positive and $72(29.0 \%)$ had HIV while others were $186(31.0 \%)$ and 41 (15.0\%) had TB, 10 (10.0\%), 4 (12.0\%) had RRMTB and 65 (26.0\%) had HIV infection respectively as shown on Figure 3.

\subsection{Prevalence of TB, TB/HIV, RRMTB and HIV by Education}

The prevalence of TB among 298 patients with tertiary education was 153 (52.0\%), TB/HV 38 (40.0\%) RRMTB 17 (48.0\%) and HIV 117 (47.0\%); subjects with secondary education were 228 the prevalence of TB was 133 (42.0\%), TB/HIV 49 (52.0\%), RRMTB 17 (48.0\%) and HIV 94 (38.0\%) respectively. Out of 48 patients with primary education 9 (3.0\%) had TB, 5 (6.0\%) had TB/HIV co-infection, 17 (48.0\%) had RRMTB and 1 (4.0\%) had HIV 27 (11.0\%) while 26 with informal education $9(3.0 \%)$ were TB positive, $2(2.0 \%)$ were TB/HIV positive and $11(5.0 \%)$ had HIV infection respectively (Figure 4$)$.

\subsection{Prevalence of TB, TB/HIV, RRMTB and HIV by Occupation}

From the 600 patients examined 4 were house wives with $0(0.00 \%)$ prevalence

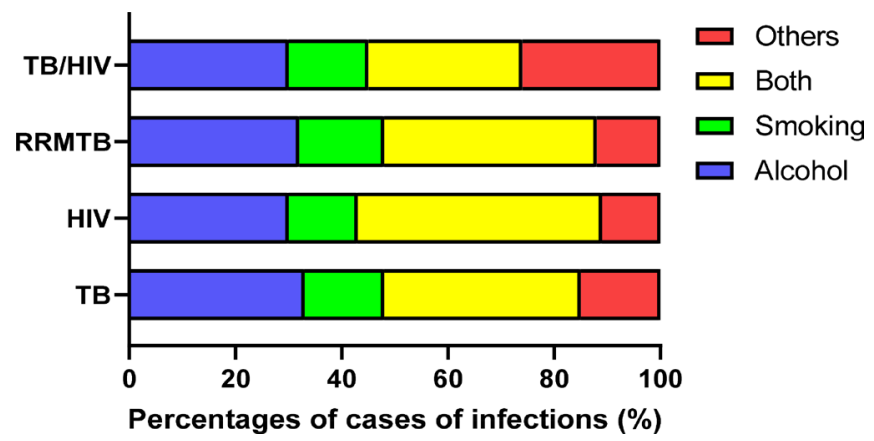

Figure 3. Prevalence of TB, TB/HIV, RRMTB and HIV by Alcoholics and Smokers. Chisquare: $15.14, \mathrm{df}=9, \mathrm{P}=0.0872$.

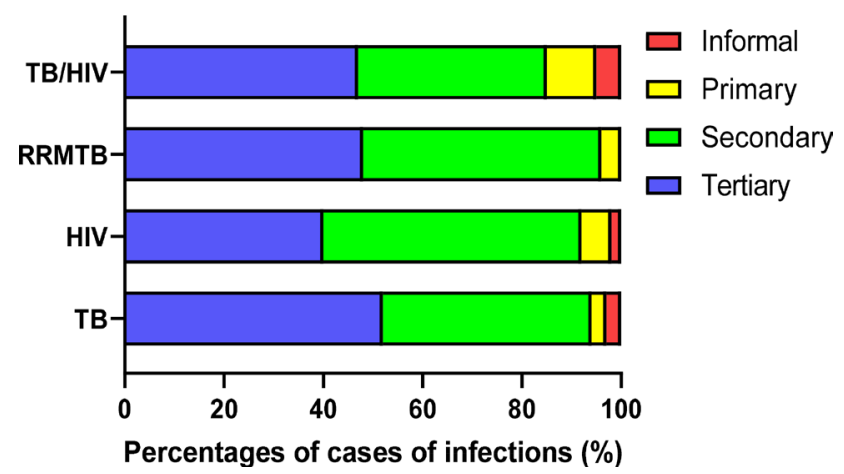

Figure 4. Prevalence of TB, TB/HIV, RRMTB, and HIV by Education. Key: Chi-square: 15.82, df: $9, \mathrm{P}=0.0077$. 
in all parameters examined, unemployed/retired were $34,20(7.0 \%)$ had TB, 3 (3.0\%) had TB/HIV, 1 (4.0\%) had RRMTB and 5 (2.0\%) were infected with HIV; while self employed subjects were 179, 103 (35.0\%) were infected with TB, 32 (34.0\%) had TB/HIV, 13 (36.0\%) had RRMTB and 72 (29.0\%) were infected with HIV; whereas civil/public servants were 165, 97 (33.0\%) were positive for TB, 21 (22.0\%) were co-infected with TB/HIV, 8 (24.0\%) had infection with RRMTB and 59 (24.0\%) were HIV infected respectively (Figure 5).

\subsection{Prevalence of TB, HIV/TB RRMTB and HIV in by Local Government Area}

The prevalence of TB, TB/HIV, RRMTB and HIV by the local government areas showed that Yenagoa had the greatest burden with total number of patients as 473 , TB positive was 235 (80.0\%), TB/HIV 72 (76.0\%), RRMTB 24 (68.5\%) and HIV $202(81.2 \%)$, followed by Southern Ijaw with 50 patients TB was 24 (8.5\%),TB/HIV 9 (9.8\%), RRMTB 6 (17.1\%) and HIV 15 (6.0\%); Ogbia 21, TB positive were 14 (4.8\%), TB/HIV 4 (4.2\%), RRMTB 3 (8.6\%) and HIV 7 (2.8\%); then Ekeremor 13 patients TB 4 (1.4\%), TB/HIV 4 (4.2\%), RRMTB 1 (2.9\%) and HIV 8 (3.2\%); Nembe 21 patients TB 7 (2.4\%), TB/HIV 1 (1.1\%), RRMTB 1 (2.9\%) and HIV 7 (2.8\%); these were followed by Brass and lastly Kolokuma/Opokuma respectively as shown on Table 2.

\section{Discussion}

The prevalence of tuberculosis obtained from this study by the Gene Xpert molecular method was $292(49.0 \%)$ and $217(73.1 .1 \%)$ by the ZN-smear staining technique. The Gene Xpert method of diagnosing TB was $100 \%$ accurate in detecting TB from this study, while the $\mathrm{ZN}$-smear technique was $73.8 \%$. Other researchers comparing the accuracy of both methods had related results. It was noted by Reechaipichitkul et al. [26] that the GeneXpert molecular method was $84 \%$ accurate compared to $48 \%$ by the $\mathrm{ZN}$-staining technique and that the performance of Gene Xpert for TB detection and its resistant strains (MTB/RIF) is enhanced. Gene Xpert achieves early diagnosis of TB for appropriate treatment and provides the opportunity to curb transmission. In another research evaluating GeneXpert and

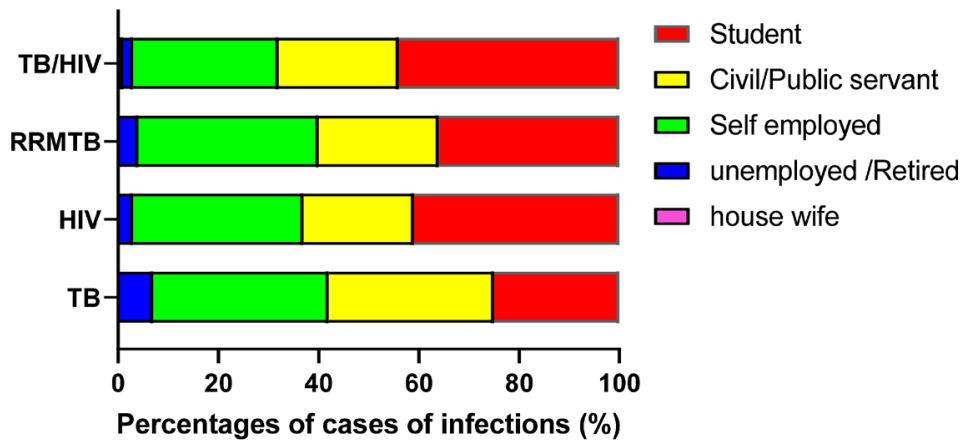

Figure 5. Prevalence of TB, TB/HIV, RRMTB and HIV Infections by Occupational. Key: Chi-square: 33.65 , df: $12, \mathrm{P}=0.0008$. 
Table 2. Prevalence of TB, HIV/TB RRMTB and HIV in by Local Government Area.

\begin{tabular}{cccccc}
\hline L. G.A & $\begin{array}{c}\text { Number } \\
\text { Examined }\end{array}$ & $\begin{array}{c}\text { TB } \\
\text { Number } \\
\text { Positive }\end{array}$ & $\begin{array}{c}\text { TB/HIV } \\
\text { Number } \\
\text { Positive }\end{array}$ & $\begin{array}{c}\text { RRMTB } \\
\text { Number } \\
\text { Positive }\end{array}$ & $\begin{array}{c}\text { HIV } \\
\text { Number } \\
\text { Positive }\end{array}$ \\
\hline Brass & 7 & $2(0.4)$ & $1(1.1)$ & $0(0.0)$ & $3(1.2)$ \\
Ekeremor & 13 & $4(1.4)$ & $4(4.2)$ & $1(2.9)$ & $8(3.2)$ \\
Kolokuma/Opokuma & 7 & $4(1.4)$ & $0(0.0)$ & $0(0.0)$ & $3(1.2)$ \\
Nembe & 21 & $7(2.4)$ & $1(1.1)$ & $1(2.9)$ & $7(2.8)$ \\
Ogbia & 21 & $14(4.8)$ & $4(4.2)$ & $3(8.6)$ & $7(2.8)$ \\
Southern Ijaw & 50 & $24(8.2)$ & $9(9.6)$ & $6(17.1)$ & $15(6.0)$ \\
Sagbama & 8 & $4(1.4)$ & $3(3.2)$ & $0(0.0)$ & $4(1.6)$ \\
Yenagoa & 473 & $235(80.0)$ & $72(76.6)$ & $24(68.5)$ & $202(81.2)$ \\
TOTAL & 600 & $294(49.0)$ & $94(15.6)$ & $35(11.9)$ & $249(41.5)$ \\
\hline
\end{tabular}

Prevalence in Parenthesis $=$ Percentages, Chi square: 22.83, df: 21, p-value $=0.3533$.

AFB smear microscopy in Enugu, Nigeria, using a total of 65 subjects with pulmonary TB 78.5\% detection was achieved by AFB smear and 100\% had TB, MTB/ RIF detected by Cepheid Gene Xpert which was similar to the finding of this study, the researchers remarked that the difference between Gene Xpert and AFB smear technique was significantly high, therefore Gene Xpert should be deemed as an indispensable tool for diagnosing TB [27]. Umair et al. [28] also recorded 60\% by $\mathrm{AFB}$ and $100 \%$ by using GeneXpert. In another work aimed at equating the performance Gene Xpert and AFB smear method [29] had 74.1\% sensitivity for GenXpert, 38.6\% for the AFB ZN-smear method. It was concluded that the Gene Xpert was far more accurate and less time-consuming than the traditional AFB method. In Benin City Nigeria, GeneXpert sensitivity was $65.7 \%$ and AFB smear technique was $38.6 \%$, it was recommended that GeneXpert molecular method be integrated for timely intervention in diagnosis and treatment of tuberculosis [30]. Akanbi et al. [31] also concluded that Gene Xpert has significantly high sensitivity but low sensitivity was observed among TB/HIV patients. Gene Xpert is accurate and rapid in detecting TB cases, less laborious, and more precise in detecting TB. Part of their result was not concurrent with that of this research because low detection of TB was not noted among TB/HIV co-infected patients using by Gene Xpert method.

The prevalence of TB from this research was 294 (49.0\%) from the DOTS center in Bayelsa, Nigeria. Other researchers had results contrary to or lower to what was obtained in this research. Alau et al. [32] recorded a low prevalence rate of $22 \%$ in global fund-supported comprehensive facilities in Nigeria, while in Calaber Crossriver State Nigeria, the prevalence obtained was 24.8\% [33] stated a prevalence of $23 \%$ in northern Nigeria. In North-Western states, Nigeria [34] had a prevalence rate of $29.2 \%$ among patients previously treated for pulmonary TB. These results were lower than the result obtained in this study. In Enugu [35] reported TB prevalence rate of 37.9\%, [36] had 37.7\% also in Enugu. 
[37] Recorded a prevalence of $38.5 \%$ in Ikot Ekpene. In Benin City, [33] obtained a prevalence rate of $44.6 \%$. The results were similar to the finding of this research. Analogous research conducted in Bayelsa, Nigeria, [38] had a high prevalence of $78.2 \%$ among patients attending DOTS centers in Yenegoa, the high prevalence might be because the study was conducted in Yenegoa town only and most patients prefer attending DOTS center in Yenegoa off their environ because of the phobia of stigmatization. In Africa, Nigeria ranks fourth among the 22 high TB burden countries with about 460,000 cases reported annually [2]. An area might have an entirely different prevalence rate based on environmental factor, habits, socio-economic status, method of analysis, and other predisposing factors that may peculiar to the area.

In the results of age groups, the age group that was most predisposed to TB, TB/HIV co-infection and HIV was age group 21 - 40 yrs with the prevalence rate of TB $47.0 \%$, TB/HIV 47.8\%, RRMTB 48\%, and HIV 51\%. [19] while studying the prevalence of TB in DOTs centers in Port Harcourt, Rivers State, Nigeria noted that the most predisposed age group was age group 21 - 40 yrs with a prevalence of $17.11 \%$, in Benue State Nigeria, the prevalence rate of TB was $37.1 \%$ and the age group with a high prevalence rate was age 21 - $40 \mathrm{yrs}$. In an analogous work [20] recorded TB, 61.5\%, and age group age 30 - 49 yrs had high prevalence rate. In Nassarawa State (Lafia), Nigeria, the prevalence of TB obtained was $34.0 \%$ also age groups 21 - 40 yrs had a high prevalence rate of 31 (43.7\%) [39]. In Burkina Faso, [40] TB was 55 (94.8\%). In studying the rural population in Edo State, Nigeria, [21] obtained a prevalence rate of 37 (58.7\%) among the age group 21 - 40 yrs. The prevalence of TB/HIV co-infection obtained from the study was $33.9 \%$ but other researchers had lower prevalence of [41] 22\%, TB/ HIV co-infection as $18.2 \%$, [41] 18.20\%, 12.7\%. TB/HIV [21] 15 (46.9\%), TB/HIV [39], age group 21 - 40 yrs had high prevalence rate among all age groups. In analogous work in Burkina Faso, [40] the prevalence of TB/HIV was $13.8 \%$ which was high among the same age group. The prevalence rates might differ but the fact is that age 20 - $40 \mathrm{yrs}$ has the greatest burden of all parameters determined. There was a significant difference among age groups using chi-square at $<0.005$. The soaring levels of social activities associated with age group $21-45 \mathrm{yrs}$ might predispose subjects within this age group to TB, HIV infections, although the results might be influenced by the method of detection, procedures of collecting samples, the locations of study, and knowledge of preventive measures for TB in a locality.

The prevalence of $\mathrm{TB}$ and $\mathrm{TB} / \mathrm{HIV}$ by gender from this study were male 53 (37.3\%), female 29 (26.8\%), men had a slightly high prevalence of TB, HIV, and RRMTB respectively. In a related study carried out in Yenagoa Bayelsa State, the overall prevalence of TB/HIV was $21.8 \%$ and by gender, the prevalence among males was 153 (41.1\%) and females 58.9\%. In other African countries [41] had high prevalence among females in Amahara region of Ethiopia 69\% and males 48 (31\%). In related work in Burkina Faso, [40] had the prevalence among males 
$10.3 \%$ and females 20.3. These findings were not concomitant with the result of this research because the male had a high prevalence if equated to female counterpart. In Lagos, Nigeria, the prevalence of TB/HIV co-infection among patients by gender were males $25.6 \%$ and females $24.8 \%$ [35] reported a prevalence of $44.6 \%$ males and females $29.6 \%$. In Ikot Ekpene Cross River State, Nigeria [33] had a prevalence of $35.6 \%$ male and female $28.6 \%$.

Fekadu [41] examining the prevalence of TB, TB/HIV co-infection among HIV infected persons in Amahora, Ethiopia, recorded a prevalence of 158 (27.7\%). It was noted that those with higher educational qualifications had a low prevalence rate of TB, HIV, and TB/HIV co-infection. He attributed this to better enlightenment by the school. The result of the study differs from that reported in Ethiopia [41] because those with higher educational qualifications had a high prevalence compared to those with primary and non-formal education. This was in agreement with the finding of [20]. The educated ones are more exposed socially at work, school, and other spheres of life hence they might be more predisposed to TB infection since infection is air born and HIV is mostly transmitted by sexual intercourse. Lack of health education or enlightenment on the modes of transmission of TB and HIV might also predispose the naive educated just like the uneducated.

The prevalence of TB was 70 (58.8\%) for alcoholics and 32 (56.1\%) for smokers. The burdens were more on the subjects that indulged in both alcohol and smoking. The habits of taking alcohol, tobacco smoking or both had been shown to activate latent TB to active infection [13]. The prevalence rate of RRMTB was $8(6.9 \%)$ among alcoholics and 4 (7.0\%) among smokers which were similar, this might indicate a similar predisposition but there was no significant difference statistically using chi-square. It had been found that alcohol and tobacco may contribute to the yoke of TB in Nigeria. Studies have pinpointed alcohol use and tobacco smoking [7]. The disruption of the host's innate and adaptive immune systems by alcohol, tobacco, or both increases vulnerability to TB and may reactivate covert TB infection [13]. Tobacco smoking may affect the immune system by disturbing the role of epithelial permeability, cilia movement, and macrophages while alcohol may directly or indirectly by toxic effects through nutrient deficiencies cause deleterious effects such as cancer and depression [11]. Tobacco smoking has been linked with cavity formation in the lungs, increased bacilli load, and a high risk of TB reactivation. Alcohol consumption of over $40 \mathrm{~g}$ per day and detection of disorder caused by it arguments the risk for TB and high smear positivity [11]. An increasing rate of HIV might be responsible for the increase in the notification of TB. It is most likely that both TB and HIV enhance the infection initiated by the other (synergy). Indulging in tobacco smoking and alcohol consumption predisposes people to tuberculosis (Figure 3).

The prevalence of TB, TB/HIV, and RRMTB by occupation, the self-employed, civil servants, and students had a high prevalence rate. Most civil servants function in offices occupied by more than one person and their jobs may require interaction with co-workers and the public, even the self-employed. For the stu- 
dents, overcrowding in schools is a major problem in developing countries such as Nigeria, and TB is transmitted by inhalation of aerosol containing the bacilli from infected individuals when talking, laughing, coughing and sneezing, etc.

Bayelsa State has eight (8) LGAs, but out of 600 subjects examined 338 (78.9\%) were from Yenegoa local government (the capital city). The fear of stigmatization as TB or HIV patient in the locality compelled some patients to seek medical attention in the capital city [19] of Yenegoa. This might be one of major the reasons for the high burden of TB and HIV in Yenegoa. The prevailing level of poverty and unemployment in developing countries might aid the transmission and progression of the disease. Most subjects coming from other local government areas to access medical facilities may not be able to bear the financial burden for appointed normal schedule visits and may break the first-line drugs treatment calendar which may induce the development of drug resistance by $M$. $t u$ berculosis.

\section{Conclusion}

The results show there is a relationship between age, educational status and occupational level and the infection pattern of tuberculosis and HIV co-infection. This could imply people within a particular age group which are very sexually active hence represent the means of transfer of the disease. Again, the education could also imply the level of awareness of the infection among the top class elites in the society.

\section{Conflicts of Interest}

The authors declare no conflicts of interest regarding the publication of this paper.

\section{References}

[1] Nardell, E.A. (2015) Transmission and Institutional Infection Control of Tuberculosis. Cold Spring Harbor Perspectives in Medicine, 6, a018192. https://doi.org/10.1101/cshperspect.a018192

[2] World Health Organization (2016) World TB Day 2016: Unite to End TB. World Health Organization, Geneva. http://www.who.int/campaigns/tb-day/2016/event/en/

[3] World Health Organization (2013) Systemetic Screening for Active Tuberculosis: Principle and Recommendation. World Health Organization, Geneva.

[4] World Health Organization (2014) Global Tuberculosis Report 2014. World Health Organization, Geneva.

[5] Pawlowski, A., Jansson, M., Sköld, M., Rottenberg, M.E. and Källenius, G. (2012) Tuberculosis and HIV Co-Infection. PLoS Pathogens, 8, e1002464. https://doi.org/10.1371/journal.ppat.1002464

[6] Zhang, L, Duan, O., Chen, C., Zhang, Z., Lu, Z., Yang, Y., et al. (2016) Tuberculosis in Mainland China. An Update Review and Meta-Analysis. PLoS ONE, 11, e0148041. https://doi.org/10.1371/journal.pone.0148041

[7] Long, Q., Qu, Y. and Lucas, H. (2016) Drug-Resistant Tuberculosis Control in Chi- 
na: Progress and Challenges. Infectious Disease of Poverty, 5, Article No. 9. https://doi.org/10.1186/s40249-016-0103-3

[8] National Centers for Disease Control and Prevention (2017) Population-Based HIV Assessment. https://www.cdc.gov/globalhivtb/index.html

[9] U.S. Agency for International Development (USAID) (2014) Report on the Twin Epidemics: HIV AND TB Co-Infection.

https://www.usaid.gov/news-information/fact-sheets/twin-epidemics-hiv-and-tb-co -infection

[10] Charles, M. and Boyle, B. (2002) Excess and Access: The Continuing Controversy Regarding HIV and Health Care in Africa. AIDS Read, 12, 288-292.

[11] Lönnroth, K., Migliori, G.B., Abubakar, I., D’Ambrosio, L., de Vries, G., Diel, R., et al. (2015) Towards Tuberculosis Elimination: An Action for Low-Incidence Countries. European Respiratory Journal, 45, 928-952. https://doi.org/10.1183/09031936.00214014

[12] Imtiaz, S., Shield, K.D., Roerecke, M., Samokhvalov, A.V., Lönnroth, K. and Rehm, J. (2017) Alcohol Consumption as a Risk Factor for Tuberculosis: Meta-Analyses and Burden of Disease. European Respiratory Journal, 50, Article ID: 1700216. https://doi.org/10.1183/13993003.00216-2017

[13] Feldman, C. and Anderson, R. (2013) Cigarette Smoking and Mechanisms of Susceptibility to Infections of the Respiratory Tract and Other Organ Systems. Journal of Infection, 67, 169-184. https://doi.org/10.1016/j.jinf.2013.05.004

[14] Ndadilnasiya, E.W., Simeon, C., Patrick, N., Olufunmilayo, F., Olajide, A.O., Hyelshilni, W., Luka, I., Oladayo, B., Saheed, G., Samuel, B., Peterside, K. and Peter N. (2014) Factors Associated with Tuberculosis among Patients Attending a Treatment Centre in Zaria, North-West Nigeria. Pan African Medical Journal, 18, Article No. 5. https://doi.org/10.11604/pamj.supp.2014.18.1.4189

[15] Wanyeki, I., Olson, S., Brassard, P., Menzies, D., Ross, N., Behr, M. and Schwartzman, K. (2006) Dwellings, Crowding, and Tuberculosis in Montreal. Social Science and Medicine, 63, 501-511. https://doi.org/10.1016/j.socscimed.2005.12.015

[16] Patterson, B. and Wood, R. (2019) Is Cough Really Necessary for TB Transmission? Tuberculosis, 117, 31-35. https://doi.org/10.1016/j.tube.2019.05.003

[17] Umeh, E.U., Ishaleku, D. and Iheukwumere, C.C. (2007) HIV/Tuberculosis Co-Infection among Patients Attending a Referral Chest Clinic in Nasarawa State, Nigeria. Journal of Applied Sciences, 7, 933-935.

https://doi.org/10.3923/jas.2007.933.935

[18] World Health Organization (2017) Global Tuberculosis Report. World Health Organization, WHO/Regional Office for Africa.

http://apps.who.int/iris/bitstream/handle/10665/329368/9789241565714-eng.pdf?ua $\equiv 1$

[19] Smart, E.A. and Constancy, P.A. (2015) Prevalence of Human Immunodeficiency Virus (HIV) among Tuberculosis Patients Attending Directly Observed Treatment Short-Course (DOTS) Clinic in Port Harcourt, Nigeria. International Journal of Science and Research, 9, 1399-1400.

[20] Osei, E., Der, J., Owusu, R., Kofie, P. and Axame W.K. (2017) The Burden of HIV on Tuberculosis Patients in the Volta Region of Ghana from 2012 to 2015: Implication for Tuberculosis Control. BMC Infectious Diseases, 17, Article No. 504. https://doi.org/10.1186/s12879-017-2598-Z

[21] Bankole, H.O., Mitsan, O., Odaro, S.I. and Adekunle, A.O. (2014) Prevalence of HIV Infection among Patients with Pulmonary Tuberculosis in a Rural Tertiary Hospital 
in Nigeria. Nigerian Journal of Experimental and Clinical Biosciences, 2, 90-94.

[22] World Health Organization (2018) Global Tuberculosis Report 2018. World Health Organization, Geneva. http://apps.who.int/iris/handle/10665/274453

[23] World Health Organization (2016) Global Tuberculosis Report. World Health Organization, Geneva. http://apps.who.int/iris/bitstream/10665/250441/1/9789241565394-eng.pdf

[24] World Health Organization (2019) World Health Organization Tuberculosis and HIV. World Health Organization, Geneva. https://www.who.int/hiv/topics/tb/about tb/en/

[25] Cheesbrough, M. (2006) District Laboratory Practice in Tropical Countries. Part 2: Ziehl-Neelsen Staining Technique. Cambridge University Press, Cambridge, 135-140. https://doi.org/10.1017/CBO9780511543470

[26] Reechaipichitkul, W., Suleesathira, T. and Chaimanee, P. (2017) Comparison of GeneXpert MTB/RIF Assay with Conventional AFB Smear for Diagnosis of Pulmonary Tuberculosis in Northeastern Thailand. Southeast Asian Journal of Tropical Medicine and Public Health, 48, 313-321.

[27] Eze, K.A., Ezigbo, E.D., Nweze, E.U.E.P., Chuka, O.E.B., Ibeagha, I. and OnwukaKalu, C. (2018) Comparative Evaluation of Genexpert MTB/RIF with AFB Smear Microscopy Methods in the Diagnosis of Tuberculosis. Journal of Health, Medicine and Nursing, 48, 77-81.

[28] Umair, M., Siddiqui, S. and Farooq M. (2020) Diagnostic Accuracy of Sputum Microscopy in Comparison with GeneXpert in Pulmonary Tuberculosis. Cureus, 12, Article No. e11383. https://doi.org/10.7759/cureus.11383

[29] Schluger, N.W. (2019) The Acid-Fast Bacilli Smear: Hail and Farewell. American Journal of Respiratory and Critical Care Medicine, 199, 691-692.

https://doi.org/10.1164/rccm.201809-1772ED

[30] Ochei, K.C., Obeagu, E.I., Mbajiuka, C.S. and Uzoije, N.U. (2014) Comparative Assessment of Five Laboratory Techniques in the Diagnosis of Pulmonary Tuberculosis in Abuja. IOSR Journal of Dental and Medical Sciences, 13, 73-78.

[31] Akanbi, M.O., Achenbach, C., Taiwo, B., et al. (2017) Evaluation of Gene Xpert for Routine Diagnosis of HIV-Associated Tuberculosis in Nigeria: A Prospective Cohort Study. BMC Pulmonary Medicine, 17, Article No. 87. https://doi.org/10.1186/s12890-017-0430-6

[32] Alau, K.K., Weaver, M.R, Ogungbemi, M.K., et al. (2016) Prevalence of Tuberculosis and HIV/AIDS Co-Infection among HIV Clients at Global Fund Supported Comprehensive Facilities in Nigeria. International Research on Medical Sciences, 4, 9195.

[33] Kooffreh, M.E., Offor, J.B., Ekerette, E.E. and Udom, U.I. (2016) Prevalence of Tuberculosis in Calabar, Nigeria: A Case Study of Patients Attending the Outpatients Department of Dr. Lawrence Henshaw Memorial Hospital, Calabar. Saudi Journal for Health Sciences, 5, 130-133.

[34] Fadeyi, A., Desalu, O.O., Ugwuoke, C., Opanwa, O.A., Nwabuisi, C. and Salami, A.K. (2017) Prevalence of Rifampicin-Resistant Tuberculosis among Patients Previously Treated for Pulmonary Tuberculosis in North-Western, Nigeria. Nigerian Journal of Medicine, 58, 161-166.

http://www.nigeriamedj.com/text.asp?2017/58/6/161/259374 https://doi.org/10.4103/nmj.NMJ 4117

[35] Nwanta, J.A., Umeononigwe, C.N., Abonyi, G.E. and Onunkwo, J.I. (2011) Retrospective Study of Bovine and Human Tuberculosis in Abattoirs and Hospitals in Enugu 
State, Southeast Nigeria. Journal of Public Health and Epidemiology, 3, 329-336.

[36] Edike, M. (2008) Nigeria Funds Threaten Enugu HIV/AIDS Campaign. Vanguard Newspaper, 1st September, 15.

[37] Itah, A.Y. and Udofia, S.M. (2005) Epidemiology and Endemicity of Pulmonarytuberculosis (PTB) in Southeastern Nigeria. Southeast Asian Journal of Tropical Medicine and Public Health, 36, 317-323.

[38] Kingston, U.O., Onuzulike, N., Ochei, K.C., Achu, E.T., Obeagu, E.I., Udah, D.C., Omorogbe, E., Ojong, E.O. and Odunze, U.G. (2017) HIV and TB Co-Infection among Patients Who Used Directly Observed Treatment Short-Course Centres in Yenagoa, Nigeria. IOSR Journal of Pharmacy and Biological Sciences, 12, 70-75.

[39] Gyar, S.D., Dauda, E. and Reuben, C.R. (2014) Prevalence of Tuberculosis in HIV/ AIDS Patients in Lafia, Central Nigeria. International Journal Current Microbiology Applied Sciences, 3, 831-838.

[40] Zingué, D.D., Hervé, H., Antoinette, K., Ganamé, Z., Adama, S., Michel, K.G., Philippe, V.D.P. and Nicolas, M. (2018) The Situation of Mycobacterium Tuberculosis Complex and HIV Co-Infection in the Hauts-Bassins Health Region, Burkina Faso. ANRS 12204/DYTRAVIHT Study. Journal of Medical Practice and Review, 2, Article No. 10.

[41] Fekadu, S., Teshome, W. and Alemu, G. (2015) Prevalence and Determinants of Tuberculosis among HIV Infected Patients in South Ethiopia. Journal of Infection in Developing Countries, 9, 898-904. https://doi.org/10.3855/jidc.5667 